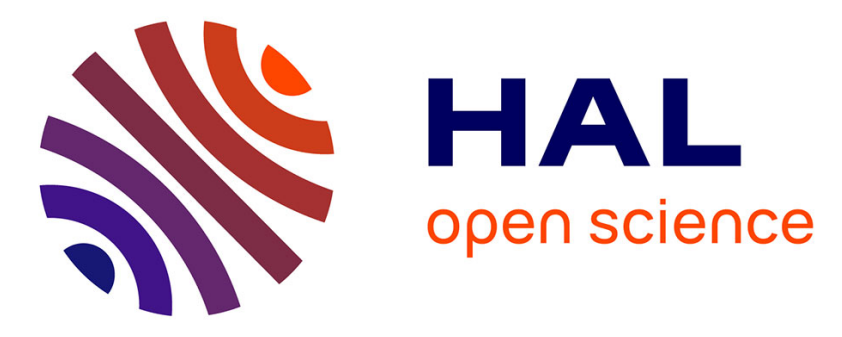

\title{
Format Effects in Volume Discounts to Consumers
}

Béatrice Parguel, Pauline de Pechpeyrou, Ouidade Sabri-Zaaraoui, Pierre

Desmet

\section{To cite this version:}

Béatrice Parguel, Pauline de Pechpeyrou, Ouidade Sabri-Zaaraoui, Pierre Desmet. Format Effects in Volume Discounts to Consumers. Journal of Product and Brand Management, 2007, 16 (5), pp.348357. halshs-00145917

\section{HAL Id: halshs-00145917 https://shs.hal.science/halshs-00145917}

Submitted on 13 Jan 2012

HAL is a multi-disciplinary open access archive for the deposit and dissemination of scientific research documents, whether they are published or not. The documents may come from teaching and research institutions in France or abroad, or from public or private research centers.
L'archive ouverte pluridisciplinaire HAL, est destinée au dépôt et à la diffusion de documents scientifiques de niveau recherche, publiés ou non, émanant des établissements d'enseignement et de recherche français ou étrangers, des laboratoires publics ou privés. 


\section{Format Effects in Volume Discounts to Consumers}

Chosen category for the paper: Research paper

Parguel B. ${ }^{1}$, De Pechpeyrou P. ${ }^{2}$, Sabri-Zaaraoui O. ${ }^{3}$ and Desmet P. ${ }^{4}$

${ }^{1}$ Béatrice PARGUEL, PhD student, Paris-Dauphine University, Paris, France 3, av. du Président Roosevelt 92330 Sceaux France, +331 47020625 beatrice.parguel@gmail.com

${ }^{2}$ Pauline DE PECHPEYROU, PhD student, ESSEC Business School and Paris-Dauphine University, Paris, France

20, rue Jean Nicot 75007 Paris France, +33 145551018

depechpeyrou@essec.fr

${ }^{3}$ Ouidade SABRI-ZAARAOUI, PhD student, Paris-Dauphine University, Paris, France

3, rue St Exupéry 92360 Meudon-la-Forêt France, +33663092369

ouidade.sabri@yahoo.fr

${ }^{4}$ Pierre DESMET, Professor, ESSEC Business School and Paris-Dauphine University, Paris, France

30, Les clairières rouges 95000 Cergy France, +33 134200640

pierre.desmet@dauphine.fr 


\begin{abstract}
Purpose

Using a classification of benefits and costs of promotional offers (Raghubir et al., 2004) along three routes - economic, informational and affective - this paper aims at evaluating, from the consumer's point of view, the relative perceptual disadvantages of separate-item bundles compared to pre-wrapped bundles.
\end{abstract}

\title{
Design/methodology/approach
}

The marketing literature and a qualitative study based on 18 consumers permit us to identify the relative perceived costs and benefits associated with separate-item bundles and to derive hypotheses. An experiment on a sample of 120 adult consumers was then set up to test these hypotheses.

\section{Findings}

The findings suggest that consumers associate separate-item bundles with higher economic benefit but also with higher inspection costs. From a more global perspective, there is no loss of interest in separate-item bundles compared to pre-wrapped bundles.

\section{Research limitations/implications}

Focusing our research on separate-item bundles clarifies the way consumers evaluate promotions. Its qualitative phase gives support to the relevance of an "informational route" (Raghubir et al., 2004), beyond the traditional utilitarian and hedonic routes (Chandon et al., 
2000). Its quantitative phase confirms the importance of cognitive biases in consumers' perceptions of promotions.

\section{Practical implications}

The numerous advantages of separate-item bundles for manufacturers and retailers and their attraction to consumers should lead to an increasingly intensive use in promotional campaigns. Besides, the quality of in-store communication is the most important factor of the success of separate-item bundles, which provides the opportunity to propose meaningful recommendations for practitioners.

\section{Originality/value of paper}

If the strengths and weaknesses of separate-item bundles have already been studied from a managerial point of view, to our knowledge, no research has focused on separate-item bundle efficiency from the consumer's point of view.

Keywords: volume discount, format effect, promotion benefits and costs, experimentation 


\section{Introduction}

Retailers use sales promotions in a very intensive manner to attract customers and increase their sales. In particular, in the volume discount sales category, bundling is a type of promotional offer in which obtaining a free product or money discount is linked to the purchase of a set number of product units (Guiltinan, 1987; Stremersch and Tellis, 2002). Implementation costs for product bundles are very high as they incur costs associated with product identification (creation of an identification barcode), product manufacturing (special packaging, specific shipping) and product management (sales previsions on a per shop basis, shelving, inventory management). Manufacturers mainly finance these costs, which represent their second spending effort, after production costs (Drèze and Bell, 2003). However, one type of bundling may avoid most of these costs. Indeed, separate-item bundles, enabled by the use of sophisticated cash registers by retailers, present the products separately, and not in a pre-wrapped format as in the case of more classic bundles. Most common examples of separate-item bundles are "buy two, get one free", "buy three, get one free" and the traditional "buy one, get one free" (1).

Interviews with experts from three fast-moving consumer goods manufacturers (Colgate/Palmolive, Unilever, Yoplait), two retailers (Auchan, Monoprix) and a firm specialized in consumer behavior analysis (Catalina) validate the claim that on the whole, pre-wrapped bundles are more expensive than separate-item ones, even though the incremental cost is difficult to assess. Indeed, separate-item bundles deliver value, drive volume, retain loyalty and build share, without modifying the processes at work at the manufacturer and retailer levels. No additional product identification, manufacturing or logistic costs are involved. As the product is a standard one, the drawbacks of unreliable sales 
forecasts (i.e., out-of-stock conditions, reconditioning of excessive stocks) are limited. These numerous advantages explain the increasing use of separate-item bundles in mass marketing. In France, separate-item bundles grew by $268 \%$ between 2000 and 2005 vs. 200\% for the prewrapped bundles, according to figures issued by the BIPP (2). In the US, Marx Promotion Intelligence, a division of TNS Media Intelligence, observes the same remarkable rise in the use of separate-item bundles and reports an increase of $48 \%$ in volume between 2004 and $2005(1)$.

If separate-item bundles are less costly than pre-wrapped bundles, retailers and manufacturers still question their relative perception by consumers: "Of course, it would be interesting to know how consumers react towards separate-item bundles. Till now, it's impossible for us to determine which technique between pre-wrapped bundles and separate-item bundles is most effective from a consumer's point of view. To do so, it would be necessary to be able to control all the factors that could affect their relative effectiveness" (the expert from Unilever). In fact, separate-item bundles are presented in a different way to pre-wrapped bundles. First, they display several prices and use different wording to describe the promotional advantage. Also, they are conditional upon certain purchase requirements (i.e., to buy a set number of product units). Finally, they suffer from a lower visibility in on-pack and in-store communication. Because of these communication specificities, the efficiency of separateitem bundles could be reduced. Indeed, past research extensively demonstrated that the communication of promotions influences perceived value and purchase intention by consumers (Compeau and Grewal, 1994; Briesch, 1997; Krishna et al., 2002; Janiszewski and Cunha, 2004). 
Using a classification of benefits and costs of promotional offers (Raghubir et al., 2004) along three routes - economic, informational and affective - the purpose of this paper is to evaluate, from the consumer's point of view, the relative perceptual disadvantages of separate-item bundles compared to pre-wrapped bundles and to provide managerial implications regarding this format's effectiveness and communication.

\section{Bundle formats presentation}

Pre-wrapped and separate-item bundles are part of price bundling techniques, which consist of the sale of two or more separate products in one package at a discount (Stremersch and Tellis, 2002). Price bundles are designed to attract shoppers' attention and ultimately entice them to buy (Seibert, 1997; Gilbert and Jackaria, 2002). In fact, price bundles are eyecatching, thus facilitating brand recognition and brand recall. In terms of sales, they encourage brand switching and even purchase acceleration (Seibert, 1997; Gilbert and Jackaria, 2002). More precisely, when consumer involvement is low, an anchoring process implies that price bundles could result in a $32 \%$ increase in sales by making salient a higher than normal purchase quantity (Wansink et al., 1998). In addition, price bundles are also able to increase consumption rate (Wansink, 1996).

Bundling, as a type of promotional offer, has recently gained a tremendous upsurge with the generalization of BOGO offers ("buy one, get one free", "buy one, get one half price", etc.). Separate-item and pre-wrapped bundles share basically the same objectives, but display special features that describe the promotional advantage to be gained from the simultaneous purchase of a set number of product units. Before presenting those features, we draw a brief typology of separate-item bundles depending on: 
- the nature of the benefit: a free product as in the case of BOGOF/B1G1F (3) ("buy one, get one free") or money discount ("buy two, get $20 \%$ off", "buy two, get one dollar on your frequent-buyer card");

- the nature of units of product to be bought: strictly identical units or units within the same product line to drive volume, increase product usage or keep the consumer out of the market and protect him from aggressive short-term competitor campaigns, units from different products of the same brand or even units from different products of different brands to drive trial or cross-merchandise;

- the number of units of product to be bought and the scale of the discount: three units for a $33 \%$ discount with the B2G1F ("buy two, get one free"), two units for a $25 \%$ discount with the B1G1HP ("buy one, get one half price"), and so on;

- the timing of the promotional advantage: it may be immediate (e.g., a free product, price cut) or deferred (e.g., credit on a frequent-buyer program).

Differences between separate-item and pre-wrapped bundles can be organized along two dimensions: the physical product itself and the communication around the bundle.

As far as the physical appearance of the bundle is concerned, we first note that unlike prewrapped bundles, separate-item bundles do not exist in themselves. It is the customer who, by picking several products, creates the bundle. Therefore, to benefit from a separate-item bundle promotional offer, consumers have to meet purchase requirements, which are validated at the checkout. In addition, unlike pre-wrapped bundles, in the case of separateitem bundles, there is no over-packaging or stickers, which immediately inform consumers that they are dealing with a promotional offer.

As far as the information around the bundle is concerned, a one-week survey of the price information shown on 244 bundles advertised through features by three major European 
retailers (Auchan, Carrefour, Champion) demonstrates that separate-item bundles advertise three prices (the price of one unit of product, the bundle price and the price per kilo or liter), when pre-wrapped bundles only advertise two prices (the bundle price and the price per kilo or liter). Therefore only separate-item bundles display the price of one unit of product. The same survey reveals that the wording of the promotional advantage is different in prewrapped bundles and separate-items bundles. Pre-wrapped bundles announce "set of three, including a free one", whereas separate-item bundles announce "buy two, get one free". As on-pack communication is impossible for separate-item bundles, the communication of the promotional offer is done through flyers displayed in store. At best, separate-item bundles are sometimes "materialized" by bags into which the customer must put the products.

Nevertheless, if separate-item bundles vary in terms of objective characteristics from prewrapped bundles, it is not actual or objective, but rather, perceived characteristics of an offer that affect consumer judgment (Jacoby and Olson, 1977; Thaler, 1985; Zeithaml, 1988). Therefore, a qualitative study by means of in-depth interviews with 18 European consumers aged 26 to 59 was conducted in November 2005 to have a more accurate insight into consumers' perceptions of these objective differences.

The results of this qualitative study show that:

- separate-item bundles and pre-wrapped bundles are perceived as similar: "I feel it is pretty much the same, you have three products and you are clearly told that the third is free";

- separate-item bundles imply a more intensive decision making process for the customer, whereas pre-wrapped bundles immediately translate into a "promotional signal": "I would 
need to think a little more to realize that if I take two I have one free. For the other example, you have both units associated and the visual impact is immediate";

- separate-item bundles are considered less visible and more difficult to understand than pre-wrapped bundles: "Some people will only pick up two items, not realizing they could get a third one free";

- separate-item bundles are associated with doubts in the effective application of the promotion: "I need to pay attention to my receipt at the checkout", when this application is considered as automatic for pre-wrapped bundles: "When the bundle is packaged together, there is no problem, it is processed with a single code". Therefore, there must be more vigilance on the part of the customer at the checkout: "I need to pay attention to my receipt at the checkout."

Consumers do perceive some of the objective characteristics that distinguish separate-item bundles from pre-wrapped bundles. These distinctions are presented as many potential perceived benefits and costs that may modify the consumer's interest in separate-item bundles compared to pre-wrapped bundles.

\section{Theoretical Framework}

In the marketing literature, the perception of the benefits and costs of promotional offers is analyzed along three different modes - economic, informational and affective - which, in turn, impact the customer's offer evaluation and purchase intention (Chandon et al., 2000; Raghubir et al., 2004). However, the literature on separate-item bundles is still scarce, and these different routes have not been applied to this specific case. 


\section{The three routes of promotional effects}

As already mentioned, the conceptual framework proposed by Raghubir et al. (2004) to understand how consumers evaluate promotional offers considers three different routes: economic, informational and affective.

The economic route deals with the monetary and non-monetary benefits and losses associated with the promotion by the consumer. The most prevalent sources of economic effect are the face value of the coupon or the amount of the discount on a bundle offer. However, nonmonetary costs, such as time and effort required for a consumer to make a decision, may be reduced by the promotion. Indeed, the promotion may simplify the decision process. These aspects were already incorporated in the Chandon et al. (2000) framework under the construct of "convenience".

The informational route describes the cognitive activity generated by the exposure to the promotional stimulus: inferences about the brand, expectations of quality, price or promotions to come, brand awareness, etc.

Finally, the affective route refers to the feelings and emotions that can emerge during all steps of the buying process. The promotion can induce positive feelings such as entertainment and exploration (Chandon et al., 2000). Moreover, consumers may feel smart when they benefit from a promotional offer (Schindler, 1989; Chandon et al., 2000).

Following this conceptual framework and taking into account the results of the preliminary study, separate-item bundles and pre-wrapped bundles are compared along these three routes.

\section{The economic route}


Separate-item bundles present the products to be sold separately, but in conjunction with an offer communicated on features and displays announcing an extra unit of product for free. Consumers may either choose to buy a single unit of the product or a set of product units in order to benefit from the promotional advantage. In this way, separate-item bundle communication on pricing contains two specific differences compared to pre-wrapped bundles communication on pricing.

First, they reflect a reference price - the single unit purchase price - in addition to the bundle price, when pre-wrapped bundles only reflect the bundle price. Specifically, when a reference price is provided, consumers use it as an anchor to assess the overall reduced sale price (Monroe, 1973; Winer, 1986), which results in a more favorable perception of the offer (Della Bitta et al., 1981; Friedmann and Haynes, 1991; Das, 1992; Chandrashekaran, 2004). As separate-item bundles display a reference price, they should drive a stronger perceived monetary benefit.

Second, separate-item bundles highlight the extra free unit of the product in a different way to pre-wrapped bundles. As an example, in the case of a $33 \%$ discount on a three-unit bundle, the separate-item bundle announces "buy two, get one free" while the pre-wrapped bundle announces "set of three, including a free one". Framing theory has consistently shown that the communication of a promotional offer directly influences consumers' perception, evaluation and buying decisions, even for an equal economic value (Tversky and Kahneman, 1974; Della Bitta et al., 1981; Wansink et al., 1998). Indeed, people are more likely to evaluate an offer favorably when it is described positively rather than negatively (Levin et al., 1998). In a series of questions used to determine preference, $91 \%$ of those surveyed indicated a clear preference for the "percent more free" format (Seibert, 1997). They believed that "more" was better, and preferred the "percent more free" wording, even when the actual amount of free product was greater in the "percent free" package. This finding should benefit 
separate-item bundles, as they stress a " $+50 \%$ " advantage ("buy two, get one free") compared to the "-33\%" advantage of pre-wrapped bundles ("set of three, including a free one").

For these two reasons, we postulate:

Hla: The perceived monetary benefit is higher for the separate-item bundle than for the pre-wrapped bundle.

The economic route proposed by Raghubir et al. (2004) also deals with the non-monetary benefits and costs associated with the promotion. Non-monetary costs have been identified in the marketing literature in the form of time, physical effort, and psychological effort (Lovelock and Wirtz, 2004). Among those costs, Youngdahl and Kellog (1997) distinguish the costs incurred by consumers who expect a service failure and have to intervene to increase their satisfaction. In this respect, the fact that consumers may have to check that the advantage is really taken into account at the checkout constitutes a specific non-monetary cost.

For separate-item bundles, the verification of the granting conditions to benefit from the promotional advantage is supposed to be automatically done at the checkout. If the "virtual" offer is not correctly coded in the checkout system, the promotional advantage is not effectively taken into account. In comparison, pre-wrapped bundles are linked to a specific identification barcode, which eliminates any error at the checkout. The qualitative study has underlined that consumers perceive the risk of not taking advantage of the promotional offer in the case of separate-item bundles, whereas they are certain about the benefit in the case of pre-wrapped bundles. Compared to pre-wrapped bundles, separate-item bundles are then associated with greater uncertainty and consequently require increased vigilance at the 
checkout to ensure that the promotional advantage is effectively accounted for. From the consumer's point of view, this translates as a greater perceived cost of inspection. Thus:

H1b: The perceived cost of inspection is higher for the separate-item bundle than for the pre-wrapped bundle.

\section{The informational route}

In the pre-wrapped bundle, units of product are wrapped in plastic film. Thus, the unusual physical dimension of the pre-wrapped bundle acts as a promotion signal for the consumer (Inman et al., 1990; Raghubir et al., 2004). In addition, a sticker is frequently integrated into the over-packaging of pre-wrapped bundles to heighten the visibility of this promotion signal. According to Inman et al. (1990), "the simple presence of a promotion signal leads the consumer to presume that the price of the promoted brand has been discounted", and the consumer immediately translates this into a good bargain. In the separate-item bundle, there is no over-packaging that could inform the consumer that he or she is dealing with a promotional offer. Consequently, an in-depth analysis of the in-store communication is needed in order to decode the promotional offer.

Furthermore, as described previously, the price information associated with separate-item bundles is more complex than that of pre-wrapped bundles. On average, separate-item bundles show three prices while pre-wrapped bundles only display two prices. Indeed, prewrapped bundles present the package with its price and the price per kilo or liter in the case of food products, whereas separate-item bundles present the basic offer (unit price and price per kilo or liter) plus details referring to the promotional offer (granting conditions and bundling price). In this context, pre-wrapped bundles may appear easier to understand. This 
proposition is further supported by the results of the qualitative phase, which have revealed that the communication of separate-item bundles is perceived as more complex than that of pre-wrapped bundles. Indeed, according to the seminal work of Estelami (1997) on multidimensional prices, increasing price complexity through the addition of new price dimensions hinders the consumer's ability to process and evaluate the displayed price information. Consequently, more effort is required to analyze the incremental amount of information.

From the above, we may conclude that from a cognitive point of view the decision processing is less costly for the pre-wrapped bundle compared to the separate-item bundle. Thus:

H2: The perceived cognitive cost associated with deal processing is higher for the separate-item bundle than for the pre-wrapped bundle.

\section{The affective route}

From what precedes, separate-item bundles may be associated with greater perceived monetary benefit as well as cognitive cost and cost of inspection than pre-wrapped bundles. The marketing literature has documented a hedonic component in the consumer's assessment of sales promotions as they provide intrinsic stimulation, fun, and self-esteem (Chandon et al., 2000). More specifically, a self-expression benefit appears when consumers respond to promotional offers to fulfill the need to be recognized as "smart-shoppers" (Schindler, 1998). This benefit is directly related to the self-attribution of the responsibility for the promotional benefit (Schindler, 1989). Undoubtedly, in the case of separate-item bundles, only buyers who have identified the promotional offer have the opportunity to take advantage of the discount. Consequently, their prerogative of paying a lower price for the separate-item bundle may lead them to feel smart and competent as shoppers (Chen et al., 1998). Furthermore, the 
more complicated it is to decode the promotional offer based on separate-item bundles, the smarter the consumer feels thanks to the importance of the self-attribution of the savings realized with this promotional offer (Estelami, 1997). Therefore, we postulate that:

H3: The perceived self-expression value associated with the deal is higher for the separate-item bundle than for the pre-wrapped bundle.

\section{The perceived interest}

Following Chandon et al. (2000), the overall evaluation of a promotion can be explained by its perceived different benefits and costs. In the same way, the global effect of the bundle format - separate-item or pre-wrapped - on the consumer's perceptions results from the combination of the effects previously discussed. More specifically, separate-item bundles should be associated with both more perceived benefits (monetary and self-expression benefits) and more perceived costs (cost of inspection, cognitive cost associated with deal processing).

Without preliminary results on the relative importance of these perceptions, we do not assume any difference in the influence of both types of bundles on the consumer's perceived interest:

H4: There is no difference in the perceived interest of the deal between separate-item bundles and pre-wrapped bundles.

Nevertheless, traditional individual determinants, such as consumption rate and deal proneness, can influence the evaluation of promotions and affect the consumer's interest in 
bundles in general and separate-item bundles in particular (Blattberg and Neslin, 1990; Lichtenstein et al., 1990, 1997; Das, 1992; Del Vecchio, 2005).

Indeed, low-volume purchasers are considered less familiar with promotions conditional on high volume purchases than high-volume purchasers. They may then perceive a stronger cost of inspection at the checkout. As the perceived cost of inspection should be more present with separate-item bundles, low-volume purchasers should exhibit a lower perceived interest in separate-item bundles than in pre-wrapped bundles. Moreover, high-volume purchasers may be more motivated by the perspective of benefiting from a monetary advantage as they have to buy numerous units of the product. As the perceived monetary benefit should be more present with separate-item bundles, high-volume purchasers should exhibit a stronger perceived interest in separate-item bundles than in pre-wrapped bundles.

Furthermore, deal-prone shoppers may be more sensitive to the self-expression benefit derived from promotions. Therefore, as this dimension should be more present with separateitem bundles than with pre-wrapped bundles, deal-prone shoppers may exhibit a stronger perceived interest in separate-item bundles than in pre-wrapped bundles.

To explore these individual influences, we will test the following hypotheses:

H5a: High-volume purchasers exhibit a stronger perceived interest in separate-item bundles than in pre-wrapped bundles, whereas low-volume purchasers exhibit a lower perceived interest in separate-item bundles than in pre-wrapped bundles.

H5b: Deal-prone shoppers exhibit a stronger perceived interest in separate-item bundles than in pre-wrapped bundles, whereas less deal-prone shoppers do not perceive any difference between separate-item bundles and pre-wrapped bundles.

\section{Methodology}


The objective of this study is to compare the perceived benefits, costs of and interest in a promotional bundle depending on its format (separate-item or pre-wrapped) for a same economic value. To meet this objective, an experiment is carried out. The differential effect is measured through a between-subjects design with subjects randomly selected. Face-to-face interviews were conducted in November 2005 in public places among 120 adult European consumers. The sample is composed of $42 \%$ men, and the average age is 37 .

The $2 \times 2$ design crosses the bundle format (pre-wrapped $v s$. separate-item) and the product category (chocolate bar vs. shower gel, two categories that intensively use promotional techniques). As "buy two, get one free" is the most popular separate-item bundle across all consumer packaged goods (1), this research focuses on an offer for a $33 \%$ discount in the form of a free product: "two units bought = the third free". The units to be bought are identical. The advantage associated with the bundle is immediate.

The selection of the two product categories is set to enable replication of results, but no particular difference is expected between the two categories. The regular prices of the chosen categories are kept comparable because they could moderate the format effects under study (Das, 1992), and reflect average market prices. Moreover, the offer is neutral and makes no reference to brand or store name. Indeed, the literature has shown that perceived brand image modifies promotional effects, such as the threshold levels and the strength of the influence of discount on attitudes or intentions (Gupta and Cooper, 1992). Besides, it has already been demonstrated that more familiar subjects with items in the bundle respond to different formats of equivalent bundles in different ways to less familiar subjects (Harlam et al., 1995). 
As can be seen in the following photographic images, the experimental manipulation corresponds to the presentation of an advertisement for the pre-wrapped bundle or the separate-item bundle.

take in Plate 1

After a selection question on product purchase and consumption rate, the advertisement is shown for a few minutes, and then withdrawn. The survey then measures all the constructs of the theoretical framework: first, the global perceived interest of the deal; second, the perceived benefits and costs associated with the offer (monetary, cognitive and selfexpression benefits and cost of inspection); and third, the individual deal-proneness. The constructs are measured on 7-point Likert scales, mostly borrowed from the literature. These items are recalled in Table I.

take in Table I

The reliability is satisfactory for the perceived interest (four items adapted from Bréchet et al., 2005; Cronbach's $\alpha=0.71$ ), the economic and hedonic benefits (three items each from Chandon et al., 2000; $\alpha=0.85$ and $\alpha=0.80$, respectively), the perceived cognitive cost associated with deal processing (four items derived from the exploratory qualitative phase; $\alpha=0.72$ ) and deal-proneness (three items from Froloff, 1992; $\alpha=0.87$ ). However, the reliability is weak for the perceived cost of inspection scale (three items from the exploratory qualitative phase; $\alpha=0.50$ ) that had not been the object of any preliminary validation. A principal component analysis has shown that all items load on the expected factor, with the exception of monetary and self-expression items, which load on the same factor. In fact, 
monetary and self-expression benefits are highly correlated, as in Batra and Ahtola (1990) and Chandon et al. (2000).

\section{Findings}

The hypotheses are tested through a multivariate analysis of variance (MANOVA). The dependent variables are the different perceived costs and benefits, as well as perceived interest. Bundle format, product category, deal-proneness and consumption rate are the factors. The constructs are measured by the mean scores of the items constituting their scale. Subjects are coded as being either high or low in deal-proneness on the basis of a mediansplit of the deal-proneness scale. The same procedure is applied to the consumption rate variable.

Neither product category nor the interaction between bundle format and product category is significant. Therefore, the data of both categories are pooled together. The multivariate analysis shows a global significant effect for the bundle format (Wilks Lamba=0.807, $\mathrm{F}=5.275, \mathrm{p}=0.000$ ). Supporting H1a, the average economic benefit perceived by participants is higher (Mean=4.76) for the separate-item bundle than for the pre-wrapped bundle (Mean=4.01, $\mathrm{p}=0.000$ ). Along with our expectations, $\mathrm{H} 1 \mathrm{~b}$ is supported: the difference in perceived cost of inspection between the separate-item bundle (Mean=3.34) and the prewrapped bundle (Mean=2.45) is highly significant $(\mathrm{p}=0.000)$. In addition, the separate-item bundle exhibits higher cognitive cost associated with deal processing (Mean=4.59 vs. 4.39, n.s.) and higher perceived self-expression value (Mean=3.67 vs. 3.42, n.s.). Although the effects are in the expected direction, the differences of means are not significant. H2 and H3 are therefore not supported. Globally, the difference of interest between the two bundles is 
not significant: the separate-item bundle does not benefit from a greater interest than the prewrapped bundle (Mean=4.93 vs. 4.70, n.s.). H4 is then supported. The results of the hypotheses tests are presented in Table II.

take in Table II

The interaction between bundle format and consumption rate is significant $(\mathrm{F}=2.217$, $\mathrm{p}=0.029$ ). High-volume purchasers in the category show a stronger perceived interest in separate-item bundles than in pre-wrapped bundles (Mean=5.24 vs. 4.62, $\mathrm{p}=0.035$ ), whereas low-volume purchasers do not perceive any difference (Mean=4.63 vs. 4.78 , n.s.). Therefore, H5a is partially supported. On the other hand, the interaction between bundle format and deal-proneness is not significant. H5b is then not supported. The results of the t-tests are presented in table III.

take in Table III

\section{Discussion}

If manufacturers and retailers both agree that separate-item bundles are less costly than prewrapped bundles, they still question their relative perception by consumers. In this research, two studies examine the consumer's perceptions of separate-item bundles compared to prewrapped bundles. The qualitative study, based on interviews with 18 consumers, reveals different benefits and costs associated with separate-item bundles. The quantitative study confirms separate-item bundles' potential disadvantage in terms of perceived cost of inspection but demonstrates their stronger perceived economic benefit. Taking into account 
both benefits and costs, separate-item bundles and pre-wrapped bundles seem to induce a similar interest from the consumer's viewpoint.

\section{Theoretical implications}

The qualitative study shows that separate-item bundles appear less visible on shelves and more complex to decode than pre-wrapped bundles. This gives support to the relevance of an “informational" route (Raghubir et al., 2004), beyond the traditional utilitarian and hedonic routes (Chandon et al., 2000) in the way consumers evaluate promotions. Moreover, the use of separate-item bundles is often linked to the uncertainty of obtaining the discount for the consumers. So, separate-item bundles may generate negative perceptions in the consumer's mind because of their lack of concreteness.

In more general terms, many studies have established that consumers' evaluations and preferences vary when presented with economically equivalent promotional deals that are worded differently (Das, 1992; Seibert, 1997; Sinha and Smith, 2000; Gendall et al., 2006). These "framing" effects are called "semantic" effects when deals are strictly equivalent on a unit-cost basis and on a total cost basis. In our experiment, the separate-item bundle announces "buy two, get one free" while the pre-wrapped bundle announces "set of three, including a free one". The economic benefit perceived by participants is higher for the separate-item bundle than for the pre-wrapped bundle. This result confirms the ordering preference found by Sinha and Smith (2000a, 2000b), where volume promotion (“'buy one, get one free") is preferred to the equivalent mixed promotion (“buy two, get 50 percent off"). This result also adds to the body of evidence that, besides the offer, its wording impacts the interest of the consumer as well as his or her purchase intention. The idea of "more" is 
preferred to the idea of "including", as in Seibert (1997), where respondents preferred the "percent more free" wording, even when the actual amount of free product was greater in the "percent free" package.

\section{Managerial implications}

The primary meaningful implication for retailers and manufacturers is that separate-item bundles offer all the characteristics that should lead to an increasingly intensive use in promotional campaigns regarding everyday use product categories. In fact, present research shows that separate-item bundles do not suffer from their invisibility in the eyes of the consumer and it is well established that they now present many advantages over pre-wrapped bundles for retailers and manufacturers. In particular, the implementation costs of bundling,

which are mainly financed by the manufacturers, are very high in the case of pre-wrapped bundles as they involve the designing of specific packaging and the creation of a new gencode (Ong et al., 1997), which are unnecessary in the case of separate-item bundles. As separate-item bundles do not require a specific manufacturing process (production capability, warehousing, shipping, and inventory), it also limits the drawbacks of an inaccurate sales forecast (i.e., out-of-stock conditions, reconditioning of excessive stocks). For the retailers too, separate-item bundles positively highlight the advantage proposed to customers and allow for an increase in sales volume without modifying the processes at the point of purchase and without requiring extra shelf space.

Moreover, separate-item bundles affect the manufacturer-retailer relationship. On the one hand, they help cement a good relationship within a trade-marketing framework (i.e., insertion in features) because this type of promotional offer is in line with retailers' expectations. On the other hand, they enable the manufacturer to move from a contractual 
promotion to an efficient promotion (Drèze and Bell, 2003). Indeed, in traditional bundles there is usually no limit on the quantity of goods that can be purchased by retailers. Therefore, they have the opportunity to "forward-buy" in order to profit from a promotional price on more units than those effectively sold to consumers during the promotional period. In such cases manufacturers subsidize the retailers' daily operations. With separate-item bundles, this potential opportunistic behavior disappears, as the incentive applies only to the units sold to consumers during the promotional event.

The second managerial implication of this research lies in the importance of in-store communication. In fact, a relevant in-store communication ensures the visibility and success of separate-item bundles, particularly when almost $90 \%$ of purchasing decisions are made at the point-of-purchase (4). For instance, it is more useful to organize weekly in-store events based on the generalization of separate-item bundles all around stores than to organize oneshot separate-item bundles. Indeed, these events may provide the opportunity to cover stores with homogeneous signs that would render more visible the products with a "virtual" promotion and "to inject some excitement back into stores" (5). Moreover, features should be used more extensively to relay those commercial in-store events and offer a pedagogical and less constraining format to explain in detail how separate-item bundles work (granting conditions and automatic process validation). Finally, the importance of the communication of separate-item bundles, from a retail perspective, illustrates the necessity for the members of a distribution channel to adopt collaborative practices. For separate-item bundles, the manufacturer has to trust the retailer to convey effectively to the consumer the promotional offer at the point-of-purchase. 


\section{Limitations and future research directions}

Three limitations of this study should be considered. First, the lack of previous research on the subject led to an exploratory process based on interviews. The perceived cost of inspection scale developed for the purpose of the study is not totally satisfactory, and its reliability has to be improved. Along the same line, the deal-proneness scale used in the questionnaire is a general one, although the results of two empirical studies favor treating deal-proneness as a domain-specific construct (Lichtenstein et al., 1995). Then, the experimentation ignores the influence of point of purchase characteristics. These elements could possibly moderate the general conclusion that separate-item bundles appear to be a more interesting solution than pre-wrapped bundles. Lastly, the experimentation does not consider the possible framing effects that have been demonstrated in the case of price bundles (Sinha and Smith, 2000; Raghubir, 2005).

In this research, we focused on bundles of strictly identical units. However, retailers and manufacturers are increasingly offering separate-item bundles composed of units from different varieties of the same product, or even from different products of the same brand. These recent variants derive a new benefit from separate-item bundles as they permit the permutation of the offer in an unlimited manner. Studying consumers' reactions to these variants of separate-item bundles constitutes a fruitful area of research, especially in the case of new product introduction.

Finally, our study took into account two individual variables frequently used in sales promotional literature (Blattberg and Neslin, 1990; Lichtenstein et al., 1990, 1997; Das, 1992; Del Vecchio, 2005). Nevertheless, other covariates could be considered in future research. First, it has been argued that the response to framing effects depends on the product category, 
whether the brand is a national brand or a store brand, the level of the discount offered, the original price of the product, and the type of store offering the discount (Gendall et al., 2006). In particular, for fast-moving consumer goods, the most effective framing of the same price discount depends on whether the product is prone to stockpiling (Gilbert and Zackaria, 2002). Second, the influence of individual covariates such as consumers' familiarity with separateitem bundles techniques (Friedmann and Haynes, 1991) and their sensitivity to environmental issues could be explored. Indeed, separate-item bundles contribute to the global reduction of over-packaging (Schwepker and Cornwell, 1991), when consumers become more concerned about the environmental consequences of their choice (6).

(1) see SN: Supermarket News, 2.13.2006 or order a free copy of the 2005 Annual FSI Trend Report on http://www.tnsmi-marx.com.

(2) see Groupe Progress - Département BIPP (Banque d'Informations Progress Promotion) website at http://www.chez.com/bipp/.

(3) see the online glossary published by PROMO Magazine to promote linguistic consistency in marketing industry, available at http://www.promomagazine.com/resourcecenter/primer/\#b.

(4) Gander, P. (2005), "See me, feel me, touch me...", Marketing Week, 06.11.05, pp. 39-40.

(5) Watson, E. (2005), “Asda says BOGOF to EDLP”, Food Manufacture, 06.13.05, p. 26.

(6) see the study produced by IPSOS on a sample of 6531 European consumers, available at http://www.ipsos.fr/CanalIpsos/articles/1332.asp. 


\section{References}

Batra, R. and Ahtola, O. (1990), "Measuring the hedonic and utilitarian sources of consumer attitudes", Marketing Letters, Vol. 2 No2, pp. 159-170.

Blattberg, R.C. and Neslin, S. (1990), Sales promotion - concepts, methods, and strategies, Prentice Hall, Englewood Cliffs, N.J.

Bréchet, A., Desmet, P. and de Pechpeyrou, P. (2005), "Effets de l'annonce d'un prix multidimensionnel sur la confiance dans la marque", International Marketing Trends Congress, Paris, January 21-22.

Briesch, R. (1997), “Does it matter how price promotions are operationalized?", Marketing Letters, Vol. 8 No 2, pp. 167-181.

Chandon, P., Wansink, B. and Laurent, G. (2000), "A benefit congruency framework of sales promotion effectiveness", Journal of Marketing, Vol. 64 No 4, pp. 65-81.

Chandrashekaran, R. (2004), "The influence of redundant comparison prices and other price presentation formats on consumers' evaluations and purchase intentions", Journal of Retailing, Vol. 80 No 1, pp. 53-66.

Chen, S., Monroe, K. and Lou, Y. (1998), "The effects of framing price promotion messages on consumers' perceptions and purchase intentions", Journal of Retailing, Vol. 74 No 3, pp. 353-372.

Compeau, L. and Grewal, D. (1994), "Adding value by communicating price deals effectively”, Pricing Strategy and Practice, Vol. 2 No 2, pp. 28-36.

Das, P. (1992), "Semantic cues and buyer evaluation of promotional communication", in Leone, R. and Kumar, V. (Eds.), AMA Educator's proceedings: enhancing knowledge development in marketing, American Marketing Association, Chicago, pp. 12-17.

Della Bitta, A., Monroe, K. and McGinnis, J. (1981), "Consumer perceptions of comparative price advertisements", Journal of Marketing Research, Vol. 18 No 4, pp. 416-427.

Del Vecchio, D. (2005), "Deal-prone consumers' response to promotion: the effects of relative and absolute promotion value", Psychology and Marketing, Vol. 22 No 5, pp. 373391.

Drèze, X. and Bell, D. (2003), "Creating win-win trade promotions: theory and empirical analysis of scan-back trade deals", Marketing Science, Vol. 22 No 1, pp. 16-39.

Estelami, H. (1997), “Consumer perceptions of multi-dimensional prices”, in Brucks, M. and MacInnis, D.J. (Eds.), Advances in Consumer Research, Vol. 24, pp. 392-399.

Friedmann, R. and Haynes, P. (1991), “An investigation of comparative price advertising in newspapers", Current Issues and Research in Advertising, Vol. 13 No 1, pp. 155-174.

Froloff, L. (1992), "La sensibilité du consommateur à la promotion des ventes: de la naissance à la maturité”, Recherche et Applications en Marketing, Vol. 7 No 3, pp. 69-88. 
Gendall, P., Hoek, J., Pope, T. and Young, K. (2006), "Message framing effects on price discounting", Journal of Product and Brand Management, Vol. 15 No 7, pp. 458-465.

Gilbert, D.C. and Jackaria, N. (2002), "The efficacy of sales promotions in UK supermarkets: a consumer view", International Journal of Retail \& Distribution Management, Vol. 30 No 6, pp. 315-322.

Guiltinan, J.P. (1987), "The price bundling of services: a normative framework", Journal of Marketing, Vol. 51 No 2, pp. 74-85.

Gupta, S. and Cooper, L.G. (1992), "The discounting of discounts and promotion thresholds", Journal of Consumer Research, Vol. 19 No 3, pp. 401-411.

Harlam, B., Krishna, A., Lehmann, D. and Mela, C. (1995), "Impact of bundle type, price framing and familiarity on purchase intention for the bundle", Journal of Business Research, Vol. 33 No 1, pp. 57-66.

Inman, J.J., McAlister, L. and Hoyer, W.D. (1990), "Promotional signal: proxy for a price cut", Journal of Consumer Research, Vol. 17 No 1, pp. 74-81.

Jacoby, J. and Olson, J.C. (1977), "Consumer response to price: an attitudinal information processing perspective", in Wind, Y. and Greenberg, M. (Eds.), Moving Ahead in Attitude Research, American Marketing Association, Chicago, pp. 73-86.

Janiszewski, C. and Cunha, Jr. (2004), "The influence of price discount framing on the evaluation of a product bundle", Journal of Consumer Research, Vol. 30 No 4, pp. 534-546.

Krishna, A., Briesch, R., Lehmann, D. and Yuan, H. (2002), "A meta-analysis of the impact of price presentation on perceived savings", Journal of Retailing, Vol. 78 No 2, pp. 101-118.

Levin, I.P., Schneider, S.L. and Gaeth, G.J. (1998), "All frames are not created equal: a typology and critical analysis of framing effects", Organizational Behavior and Human Decision Processes, Vol. 76 No 2, pp. 149-188.

Lichtenstein, D.R., Netemeyer, R.G. and Burton, S. (1990), "Distinguishing coupon proneness from value consciousness: an acquisition-transaction utility theory perspective", Journal of Marketing, Vol. 54 No 3, pp. 54-67.

Lichtenstein, D.R., Netemeyer, R.G. and Burton, S. (1995), "Assessing the domain specificity of deal proneness: a field study", Journal of Consumer Research, Vol. 22 No 3, pp. 314-326.

Lichtenstein, D.R., Burton, S. and Netemeyer, R.G. (1997), "An examination of deal proneness across sales promotion types: a consumer segmentation perspective", Journal of Retailing, Vol. 73 No 2, pp. 283-297.

Lovelock, C.H. and Wirtz, J. (2004), Services marketing: people, technology, strategy, Prentice Hall, Upper Saddle River, N.J.

Monroe, K.B. (1973), "Buyers' subjective perceptions of price", Journal of Marketing Research, Vol. 10 No 1, pp. 70-80. 
Ong, B.S., Ho, F.N. and Tripp, C. (1997), "Consumer perceptions of bonus packs: an exploratory analysis”, Journal of Consumer Marketing, Vol. 14 No 2, pp. 102-112.

Raghubir, P. (2005), "Framing a price bundle: the case of "buy/get" offers", Journal of Product and Brand Management, Vol. 14 No 2, pp. 123-128.

Raghubir, P., Inman, J.J. and Grande, H. (2004), "The three faces of consumer promotions", California Management Review, Vol. 46 No 4, pp. 23-42.

Schindler, R.M. (1989), "The excitement of getting a bargain: some hypotheses concerning the origins and effects of smart-shopper feelings", in Srull, T.K. (Ed.), Advances in Consumer Research, Vol. 16 No 1, UT: Association for Consumer Research, Provo, pp. 447-453.

Schindler, R.M. (1998) "Consequences of perceiving oneself as responsible for obtaining a discount: evidence for smart-shopper feelings", Journal of Consumer Psychology, Vol. 7 No 4, pp. 371-392.

Schwepker, C.H. and Cornwell, T.B. (1991), "An examination of ecologically concerned consumers and their intention to purchase ecologically packaged products", Journal of Public Policy and Marketing, Vol. 10 No 2, pp. 77-101.

Seibert, L.J. (1997), "What consumers think about bonus pack sales promotions", Marketing News, Vol. 31 No 4, p. 9.

Sinha, I. and Smith, M.F. (2000), "Consumer's perceptions of promotional framing of price”, Psychology and Marketing, Vol. 17 No 3, pp. 257-275.

Stremersch, S. and Tellis, G. (2002), "Strategic bundling of products and prices: a new synthesis for marketing”, Journal of Marketing, Vol. 66 No 1, pp. 55-72.

Thaler, R. (1985), "Mental accounting and consumer choice", Marketing Science, Vol. 4, No 3, pp. 199-214.

Tversky, A. and Kahneman, D. (1974), "Judgment under uncertainties: heuristics and biases", Science, Vol. 185 No 4157, pp. 1124-1131.

Wansink, B. (1996), “Can package size accelerate usage volume?”, Journal of Marketing, Vol. 60 No 3, pp. 1-14.

Wansink, B., Kent, R.J. and Hoch, S.J. (1998), “An anchoring and adjustment model of purchase quantity decisions", Journal of Marketing Research, Vol. 35 No 1, pp. 71-81.

Winer, R.S. (1986), "A reference price model of brand choice for frequently purchased products", Journal of Consumer Research, Vol. 13 No 2, pp. 250-256.

Youngdahl, W.E. and Kellogg, D. (1997), "The relationship between service customers' quality assurance behaviors, satisfaction, and effort: a cost of quality perspective", Journal of Operations Management, Vol. 15 No 1, pp. 19-32.

Zeithaml, V.A. (1988), "Consumer perceptions of price, quality, and value: a means-end model and synthesis of evidence", Journal of Marketing, Vol. 52 No 3, pp. 2-22. 
Plate 1: Photographic images of experimental stimuli

The pre-wrapped bundle

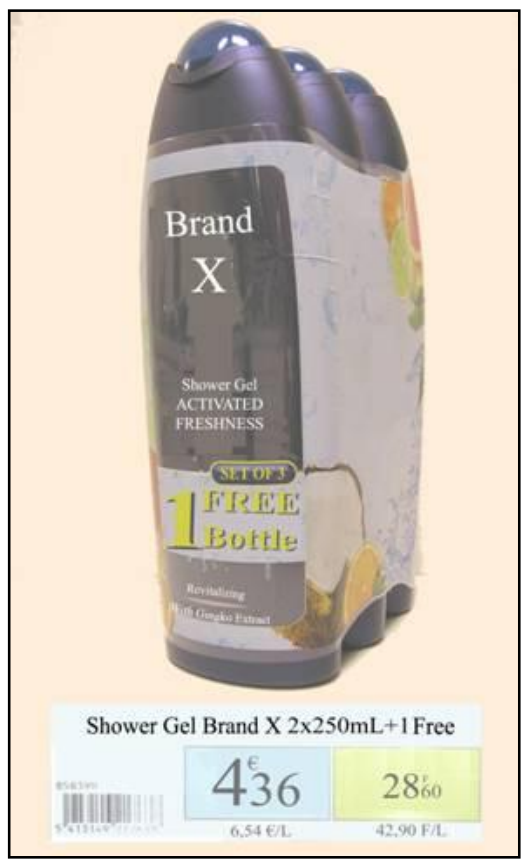

The separate-item bundle

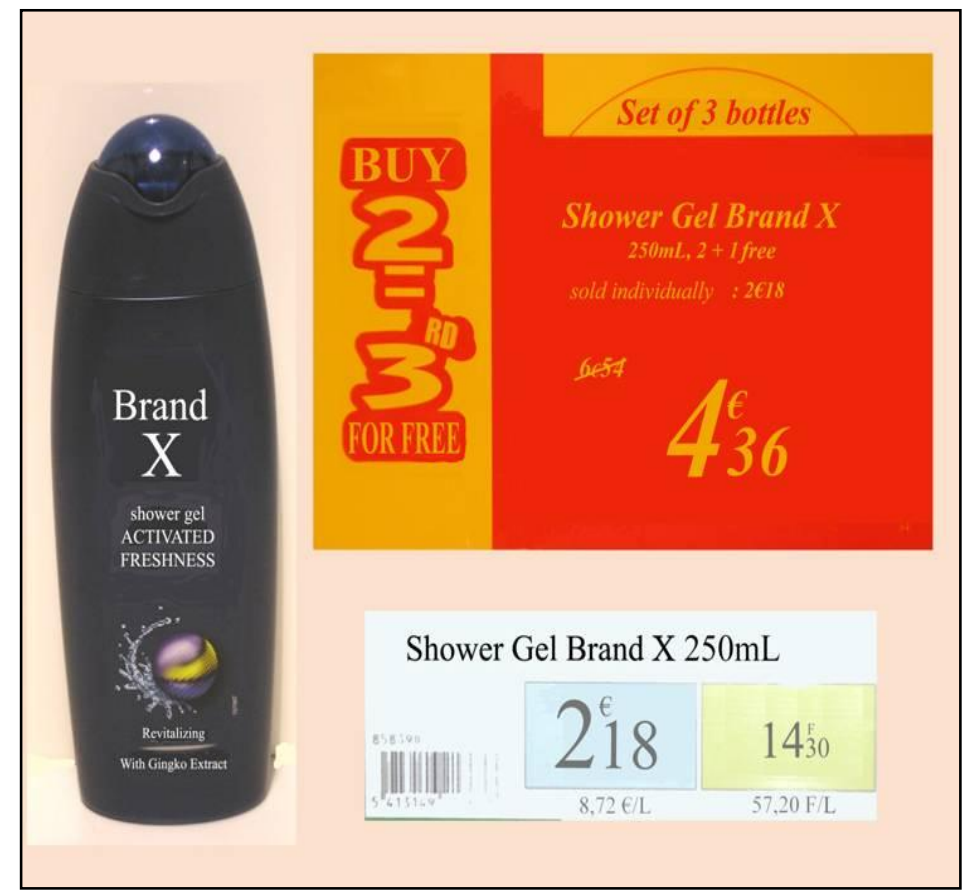




\section{Table I: Multi-item scales}

\begin{tabular}{|c|c|}
\hline $\begin{array}{l}\text { Perceived } \\
\text { monetary } \\
\text { benefit }\end{array}$ & $\begin{array}{l}\text { - With this promotion, I am doing a good deal } \\
\text { - With this promotion, the price is really less expensive } \\
\text { - With this promotion, I am saving money }\end{array}$ \\
\hline $\begin{array}{l}\text { Perceived cost } \\
\text { of inspection }\end{array}$ & $\begin{array}{l}\text { - I am sure that the promotional price will be applied by the cashier } \\
\text { - I have to check the reduction on my receipt } \\
\text { - I have to point out this promotion at the checkout }\end{array}$ \\
\hline $\begin{array}{l}\text { Perceived self- } \\
\text { expression } \\
\text { value }\end{array}$ & $\begin{array}{l}\text { - If I bought this offer, I would feel proud of having done a good deal } \\
\text { - It is an offer that I could recommend to my entourage } \\
\text { - I would be happy to have taken advantage of this offer }\end{array}$ \\
\hline $\begin{array}{c}\text { Perceived } \\
\text { cognitive cost }\end{array}$ & $\begin{array}{l}\text { - I can see immediately what may be of interest for me } \\
\text { - This promotion points out immediately the good deal } \\
\text { - This promotion prevents me from wasting time comparing products } \\
\text { - What is proposed is easy to understand }\end{array}$ \\
\hline $\begin{array}{l}\text { Perceived } \\
\text { interest }\end{array}$ & $\begin{array}{l}\text { - This offer seems interesting } \\
\text { - If I have to buy X now, I would take this offer into account } \\
\text { - This offer does not concern me } \\
\text { - It is really in my interest to take advantage of this offer }\end{array}$ \\
\hline $\begin{array}{c}\text { Deal- } \\
\text { proneness }\end{array}$ & $\begin{array}{l}\text { - While buying, I notice price cuts on } X \\
\text { - While buying, I look at price cuts on X } \\
\text { - While buying, my attention is drawn to price cuts on X }\end{array}$ \\
\hline
\end{tabular}


Table II: Perceived benefits and costs of separate-item versus pre-wrapped bundles

\begin{tabular}{|l|c|c|c|c|c|c|}
\cline { 2 - 6 } \multicolumn{1}{c|}{} & \multicolumn{2}{c|}{$\begin{array}{c}\text { Pre-wrapped } \\
\text { bundles }\end{array}$} & \multicolumn{2}{c|}{$\begin{array}{c}\text { Separate-item } \\
\text { bundles }\end{array}$} & \multirow{2}{*}{ F } & \multicolumn{1}{c|}{$\begin{array}{c}\text { p-value } \\
\text { (unilateral) }\end{array}$} \\
\cline { 2 - 6 } \multicolumn{1}{c|}{} & Mean & Std dev. & Mean & Std dev. & & \\
\hline Perceived monetary benefit & 4.01 & 1.49 & 4.76 & 1.33 & 11.279 & 0.000 \\
\hline Perceived cost of inspection effort & 2.45 & 1.25 & 3.34 & 1.43 & 13.440 & 0.000 \\
\hline Perceived cognitive benefit & 4.39 & 1.31 & 4.59 & 1.25 & 0.946 & 0.166 \\
\hline Perceived self-expression value & 3.42 & 1.67 & 3.67 & 1.42 & 0.959 & 0.164 \\
\hline Perceived interest & 4.70 & 1.27 & 4.93 & 1.18 & 1.229 & 0.135 \\
\hline
\end{tabular}


Table III: Effects of individual determinants on perceived interest

\begin{tabular}{|c|c|c|c|c|}
\hline & & \multicolumn{2}{|c|}{ Mean } & \multirow{2}{*}{$\begin{array}{c}\mathrm{p} \text {-value } \\
\text { (unilateral) }\end{array}$} \\
\hline & & $\begin{array}{c}\text { Pre-wrapped } \\
\text { bundles }\end{array}$ & $\begin{array}{c}\text { Separate-item } \\
\text { bundles }\end{array}$ & \\
\hline \multirow{2}{*}{ Consumption rate } & High & 4.62 & 5.24 & 0.035 \\
\hline & Low & 4.78 & 4.63 & 0.301 \\
\hline \multirow{2}{*}{ Deal-proneness } & High & 5.02 & 5.20 & 0.274 \\
\hline & Low & 4.32 & 4.63 & 0.173 \\
\hline
\end{tabular}

